\title{
Effect of Tetrafluorethane and Sulfur Hexafluoride Plasma Treatment on Wettability of Boron Nitride Nano-Sheets
}

\author{
H. $\operatorname{LiU}^{a, b, *}$, X. WANG ${ }^{a}$, Z. $\operatorname{LAN}^{a}$, S. $\operatorname{LiU}^{a}$ \\ ${ }^{a}$ School of Physics and Electronic Information Engineering, Huanggang Normal University, Huanggang, China \\ ${ }^{b}$ Department of Basic Courses, Wuhan Donghu University, Wuhan, China
}

(Received April 11, 2019; revised version May 13, 2019; in final form May 17, 2019)

\begin{abstract}
Boron nitride nanosheets (BNNS) consisting of 2D hexagonal boron nitride nano-layers were deposited, onto silicon substrates, via chemical vapour deposition process at $1000^{\circ} \mathrm{C}$. The BNNS were functionalized in argon plasma admixed with sulfur hexafluoride $\left(\mathrm{SF}_{6}\right)$ or tetrafluorethane $\left(\mathrm{C}_{2} \mathrm{H}_{2} \mathrm{~F}_{4}\right)$ gases. Scanning electron microscope (SEM), High resolution transmission electron microscope (HRTEM), X-ray photoelectron spectroscopy (XPS), and Water contact angle (WCA) measurements were used to characterize the BNNS before and after plasma modification. Significant changes in the surface features, upon plasma treatments of the BNNS, were noticed during scanning and transmission electron microscopy examinations. The XPS analyses revealed an extensive surface fluorination in the case of $\mathrm{Ar} / \mathrm{SF}_{6}$ plasma, while formation of fluoro-carbon layer coating on the surface of BNNS was noticed in the case of $\mathrm{Ar} / \mathrm{C}_{2} \mathrm{H}_{2} \mathrm{~F}_{4}$ plasma. Furthermore, the plasma treatments made BNNS super-hydrophobic with a contact angle as high as $167.9^{\circ}$ compared to $118.2^{\circ}$ for the untreated BNNS. The wettability of the nanostructures, as measured form the water contact angle measurements, is discussed by referring to changes in surface chemistry and morphology after plasma treatment. The stability of BNNS at high temperatures, coupled with plasma treatment can make this material a potential candidate as super-hydrophobic coating for self-cleaning application at the industrial level.
\end{abstract}

DOI: 10.12693/APhysPolA.136.467

PACS/topics: boron nitride, nano-sheets, XPS, contact angle, plasma treatment, super-hydrophobic

\section{Introduction}

Boron nitride $(\mathrm{BN})$ nanostructures are boron nitride (BN) based materials consisting of stacked hexagonal BN layers that are assembled in sheets or tubes (case of BN nano-sheets or BN nanotubes, respectively) with high aspect ratio [1-4]. These low-dimensional nanostructures are structurally identical to graphene or carbon nanotubes (CNTs) [5, 6], and exhibit many fascinating properties for advanced applications [1-9]. However, in contrast to graphene or CNTs, which are conductor or semiconductors, BN nanostructures are electrically insulator $[5,6]$. This makes them a hot research topic in different applications including dielectric substrates, far-ultraviolet light-emitting, high performance electronic devices and smart coating [1-9]. Concerning smart coating, and except for some BN nanotubes which are super-hydrophobic $[10,11]$, the other BN nanostructures including nano-sheets [12-14], and few atomic layers [15], have shown a good hydrophobicity character (with contact angle (CA) around $100-120^{\circ}$ ). However, super super-hydrophobicity (water on a surface with a CA reaches $150^{\circ}$ ) is needed for practical application such as microelectronic, biomedical and catalysts. In addition, super hydrophobic coatings possess

*corresponding author; e-mail: zhonghualiu02@gmail.com an important role in anticorrosion, resisting water coalescence, and fog condensation systems $[14,16]$. Superhydrophobic surfaces are usually made of organic materials such as polymers [16], electro-deposited gold cluster films [17], porous alumina [18], dense CNT carpets [19], $\mathrm{ZnO}$ [20], or $\mathrm{TiO}_{2}$ nanowires [21]. However, most of these materials do not stand high temperatures and harsh environment. BN nanostructures possess good chemical inert and stability at high temperatures [22]. Therefore, increasing the hydrophobicity, and extending it to other boron nitride nanostructures, is a promising route toward industrial application. It is worth mentioning that to the best to the authors' knowledge, there are very few reports on super-hydrophobic BN coating and especially in the case of boron nitride nanosheets (BNNS). For instance, Pakdel et al. [14], have reported the effect of the synthesis temperature to increase the hydrophobicity of these nanostructures. The same authors have also reported the effect of boron nitride nanosheets hybridized with graphitic domains to fabricate superhydrophobic nanosheets [23]. In this work, we present plasma treatment process to turn BNNs from hydrophobic to super-hydrophobic by means of low-pressure plasmas generated by electrical discharges in sulfur hexafluoride $\left(\mathrm{SF}_{6}\right)$ or tetrafluorethane $\left(\mathrm{C}_{2} \mathrm{H}_{2} \mathrm{~F}_{4}\right)$ gas mixtures. Herein, the plasma treatment improved the hydrophobicity of BNNS treated with $\mathrm{Ar} / \mathrm{C}_{2} \mathrm{H}_{2} \mathrm{~F}_{4}$ plasma, while it turned the BNNS to super-hydrophobic in the case of $\mathrm{Ar} / \mathrm{SF}_{6}$ plasma treatment. Indeed, the plasma treatments affected the surface chemistry as well as the 
nano/micro features of the BNNS surface. The results are analysed and discussed in context with wettability and surface chemistry/morphology properties of the plasma-modified BNNS. The plasma process, used in this work, is controllable, cheap, and scalable at the industrial level. The presented results are important for targeted utilization of BNNS as super-hydrophobic smart coating that can operate at high temperatures and harsh environment.

\section{Experimental procedure}

\subsection{Boron nitride nanosheets (BNNS) synthesis}

The BNNS were synthesised in a home-made CVD reactor. The $\mathrm{Si} / \mathrm{SiO}_{2}$ substrates were placed over an alumina combustion boat loaded with $30 \mathrm{mg}$ of precursor powder (B:MgO:FeO in a 3:2:1 M ratio). This setup was loaded inside a closed-end quartz tube, and the whole setting was positioned in a horizontal tube furnace with the substrates facing upward. The precursor and substrate were then heated up to $1000^{\circ} \mathrm{C}$ with an ammonia $\left(\mathrm{NH}_{3}\right)$ flow of $300 \mathrm{sccm}$ for $30 \mathrm{~min}$. All chemicals and reagents were used without any purification and were obtained from Sigma-Aldrich.

\subsection{Plasma-treatment}

The functionalization of BNNS surfaces was performed with low pressure plasmas generated in $\mathrm{Ar} / \mathrm{C}_{2} \mathrm{H}_{2} \mathrm{~F}_{4}$ or $\mathrm{Ar} / \mathrm{SF}_{6}$ gas mixtures at fixed flow ratio. The samples were placed on the grounded electrode of a parallelplate RF discharge. The functionalization conditions used in the present experiments were as follows: Ar to gas $\left(\mathrm{C}_{2} \mathrm{H}_{2} \mathrm{~F}_{4}\right.$ or $\left.\mathrm{SF}_{6}\right)$ flow ratio (in sccm) 10:25, pressure $\approx 10-20 \mathrm{~Pa}, \mathrm{RF}$ power $40 \mathrm{~W}$, and treatment time $10 \mathrm{~min}$. The samples were treated with $\mathrm{Ar} / \mathrm{C}_{2} \mathrm{H}_{2} \mathrm{~F}_{4}$ and $\mathrm{Ar} / \mathrm{SF}_{6}$ plasmas with fixed flow ratio.

\subsection{Materials characterization}

The samples were characterized under scanning electron microscope (SEM; JEOL 7500F) and transmission electron microscope (TEM; H9000-NAR, Hitachi). For TEM examination, the specimens were prepared by scratching the plasma-treated samples with a diamond tip and collecting the debris over a TEM copper grid covered with a thin holey carbon film. The TEM was operated at an accelerating voltage of $300 \mathrm{keV}$. Although the operating voltage is greater than the knockon damage threshold of 74 and $84 \mathrm{keV}$ for the $\mathrm{B}$ and $\mathrm{N}$ atoms, respectively [24], the BNNS were examined for very brief times and at reduced illumination to avoid any knock-on damage to the nanosheets. This approach has been reported to be quite effective in many earlier works $[25,26]$.

For surface chemical analysis, XPS measurements were carried out on K-Alpha (Thermo Scientific, East Grinstead, England) using a monochromatic (Al $\left.\mathrm{K}_{\alpha}\right)$
$\mathrm{X}$-ray beam, on a $300 \times 300 \mu \mathrm{m}^{2}$ spot area in a spectrometer equipped with a flood gun for charge compensation. The C $1 s$ line at $284.4 \mathrm{eV}$ was used as a reference to correct the binding energies for charge energy shift. A Shirley background was subtracted from the spectra and the symmetric Gaussian functions were used during peak-fitting procedure.

The condensation experiments and contact angle measurements were made to determine wettability. The contact angle measurements were performed using a KSV CAM101 instrument consisting of a single compact unit equipped with FireWire video camera of $640 \times 480$ pixels resolution, a test stand, a standard syringe and an LED source. The contact angles were measured using a wetting liquid. The experiments were performed at room temperature by placing a drop of about $1 \mu \mathrm{L}$ of distillate water on the surface. All the experiments were carried out few days after plasma-assisted treatment of the BNNS samples.

\section{Results and discussion}

The top view scanning electron micrographs (SEM), that show the surface morphologies of the asdeposited BNNS and BNNS after plasma treatment, are presented in Fig. 1. The as-deposited BNNS (Fig. 1a) are noticed to exhibit highly bent and crumpled structural morphology. Indeed, the BNNS appear to be irregularly shaped with lateral surface area. Upon plasma treatment with $\mathrm{Ar} / \mathrm{C}_{2} \mathrm{H}_{2} \mathrm{~F}_{4}$ (Fig. 1b), there is a clear apparent change in the surface morphology of the treated BNNS. The BNNS are covered with a conformal thin film (probably a fluorocarbon layer) after the treatment in $\mathrm{Ar} / \mathrm{C}_{2} \mathrm{H}_{2} \mathrm{~F}_{4}$, which conducts to the increase of the walls dimension. Moreover, when the wall's edges are being rounded, we observe that the deposited film tend to cover the walls. The surface morphology of $\mathrm{SF}_{6}$ plasma treated BNNS is presented in Fig. 1c. The most signifcant modifcation observed upon $\mathrm{SF}_{6}$ plasma exposure is the quality of the SEM images, which becomes more blurred with less morphological details and some damage of the edges, most probably because of surface charging effects due to attachment of fluorine-related radicals onto the BNNS.

For better examination of the surface morphology of the BNNS before and after plasma treatment, TEM measurements were performed, as shown in Fig. 2. The low magnification micrograph in Fig. 2a shows BNNS with bending and scrolling morphology at or near their edges. High-resolution TEM (HRTEM) images, from rectangular region of Fig. 2a (Fig. 2b) show highly ordered lattice fringes, indicating that the BNNS are crystalline with high purity. The spacing between adjacent fringes is around $\sim 0.34 \mathrm{~nm}$, which is characteristic of the (002) inter-planar distance of h-BN [27]. The HRTEM image of BNNS after' Ar/SF6 plasma treatment is shown in Fig. 2c. It reveals that the surface is covered by a kind of amorphous layer with a thickness 

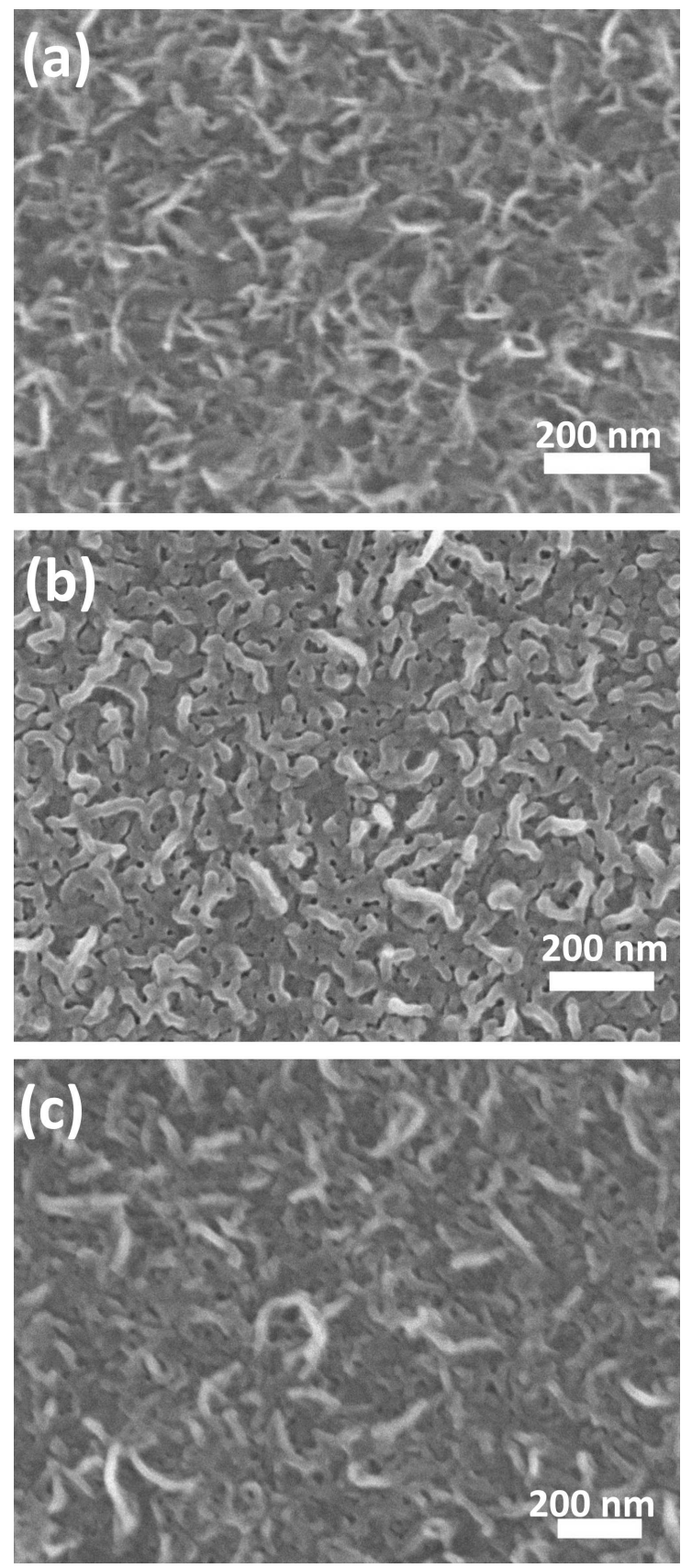

Fig. 1. Top view SEM micrographs of (a) asprepared BNNS, (b) treated with $\mathrm{Ar} / \mathrm{C}_{2} \mathrm{H}_{2} \mathrm{~F}_{4}$ plasma and (c) treated with $\mathrm{Ar} / \mathrm{SF}_{6}$ plasma.

of around $1 \mathrm{~nm}$, which appears, as shown with the arrows to be turbostratic $\mathrm{BN}$ ( $\mathrm{t}-\mathrm{BN})$. This indicates a surface damage and etching of BNNS surface in a good agreement of SEM image (Fig. 1c). Figure $2 \mathrm{~d}$ shows HRTEM image of BNNS after $\mathrm{Ar} / \mathrm{C}_{2} \mathrm{H}_{2} \mathrm{~F}_{4}$ plasma treatment. In this case, it is clear that the walls are entirely covered by a coating layer which appears to be amorphous. The layer thickness is around $5 \mathrm{~nm}$ (as shown in the inset image) and it is believed to be fluorocarbon layer which confirms the SEM observation (Fig. 2a).
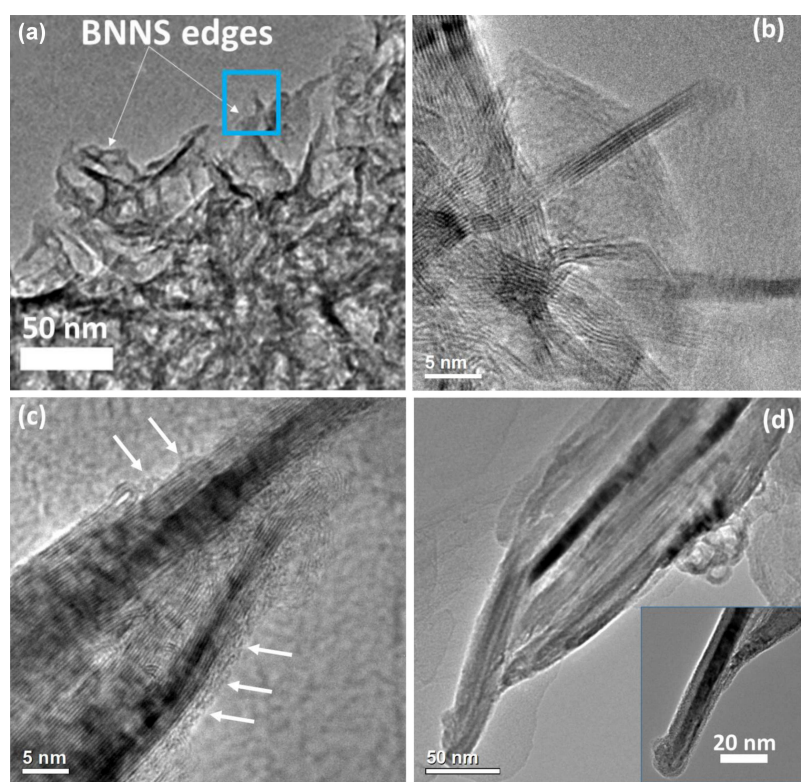

Fig. 2. (a) Low-magnification TEM image of the BNNS synthesized at $1000^{\circ} \mathrm{C}$, (b) HRTEM image of BNNS without plasma treatment (of the rectangular region in Fig.2 a), (c) HRTEM image of BNNS after treatment with $\mathrm{Ar} / \mathrm{SF}_{6}$ plasma, (d) HRTEM image of BNNS after treatment with $\mathrm{Ar} / \mathrm{C}_{2} \mathrm{H}_{2} \mathrm{~F}_{4}$ plasma, with inset showing deposition of fluorocarbon layer on the wall.

XPS survey spectra analyses (shown in Fig. 3) were performed on as-prepared and plasma-treated BNNS, with the aim at investigating the surface chemistry of BNNS after plasma treatment. In the case of untreated sample (Fig. 3a), the spectrum shows the presence of carbon $(\mathrm{C})$, nitrogen $(\mathrm{N})$, boron $(\mathrm{B})$, and oxygen $(\mathrm{O})$ elements. The constituent elements, which are $\mathrm{B}$ and $\mathrm{N}$, are represented by their respective intense lines. The $\mathrm{C}$ and $\mathrm{O}$ elements with low intensity comes from surface contamination or/and defects. It is worth to mention that, the very low intensity of $\mathrm{O} 1 \mathrm{~s}$ peak indicates high purity of the as-deposited BNNS. The survey spectrum of BNNS treated with $\mathrm{Ar} / \mathrm{SF}_{6}$ plasma (Fig. 3b) shows the presence of additional and intense peak that is related to fluorine element ( $\mathrm{F} 1 s$ ), but without any signature of sulfur element. Furthermore, it can be noticed that there is an increase of $\mathrm{O} 1 s$ peak compared with the as-deposited BNNS and a decrease of $\mathrm{N}$ $1 s$ and $\mathrm{B} 1 s$ related intensities. This can be attributed to the extensive surface oxidation due to $\mathrm{Ar} / \mathrm{SF}_{6}$ plasma treatment in a good agreement with TEM observation (Fig. 2c). In the case of $\mathrm{Ar} / \mathrm{C}_{2} \mathrm{H}_{2} \mathrm{~F}_{4}$ plasma the survey spectrum is completely different. One can notice only the presence of fluorine element (F 1s) and carbon element $(\mathrm{C} 1 s)$ with very low intense $\mathrm{O} 1 s$ related peak, but without any trace of nitrogen or boron elements. This collaborates well with the TEM observation (Fig. 2d) and confirms that the BNNS surface is completely covered with fluorocarbon layer. 

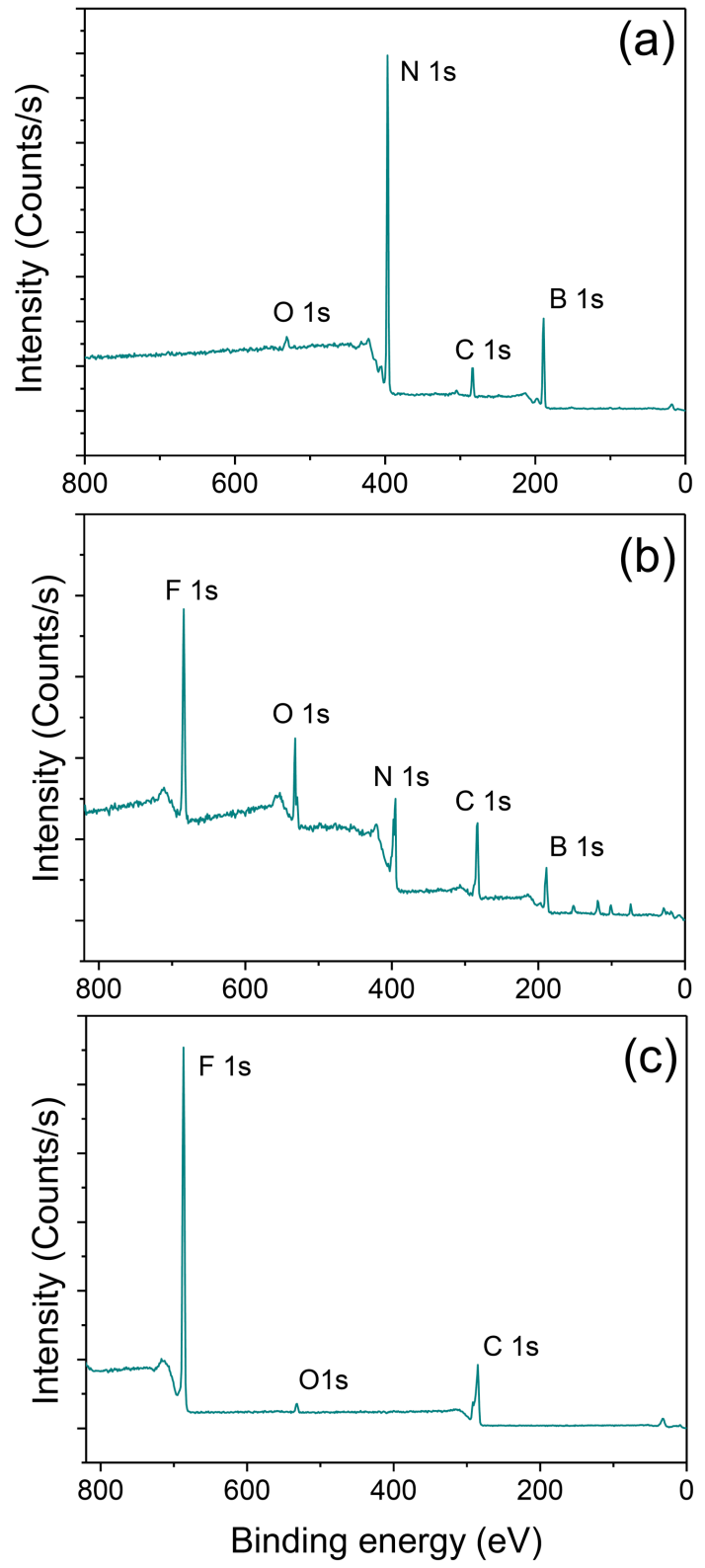

Fig. 3. XPS survey spectra of BNNS (a) before and (b) after plasma treatment in (b) $\mathrm{Ar} / \mathrm{SF}_{6}$, and (c) $\mathrm{Ar} / \mathrm{C}_{2} \mathrm{H}_{2} \mathrm{~F}_{4}$.

The deconvoluted high resolution $\mathrm{B} 1 s$ of the asprepared and plasma-treated BNNS samples are presented in Fig. 4 . The B $1 s$ spectrum of the as-made sample (Fig. 4a) can be decomposed into two peaks, the intense one at $\sim 190.0 \mathrm{eV}$ is attributed to BN bonds in hBN [28-30] and the second one at $\sim 190.8 \mathrm{eV}$ can be assigned to boron atoms simultaneously bonded to oxygen and nitrogen (N-B-O) $[28,29]$. After $\mathrm{Ar} / \mathrm{SF}_{6}$ plasma treatment (Fig. 4b), the peak related to h-BN was noticed to completely disappear with the appearance of two new peaks, the first one at binding energy of $191.4 \mathrm{eV}$ and can be assigned to B-F bond [31, 32] and a second new peak at $193.0 \mathrm{eV}$ which can be assigned to
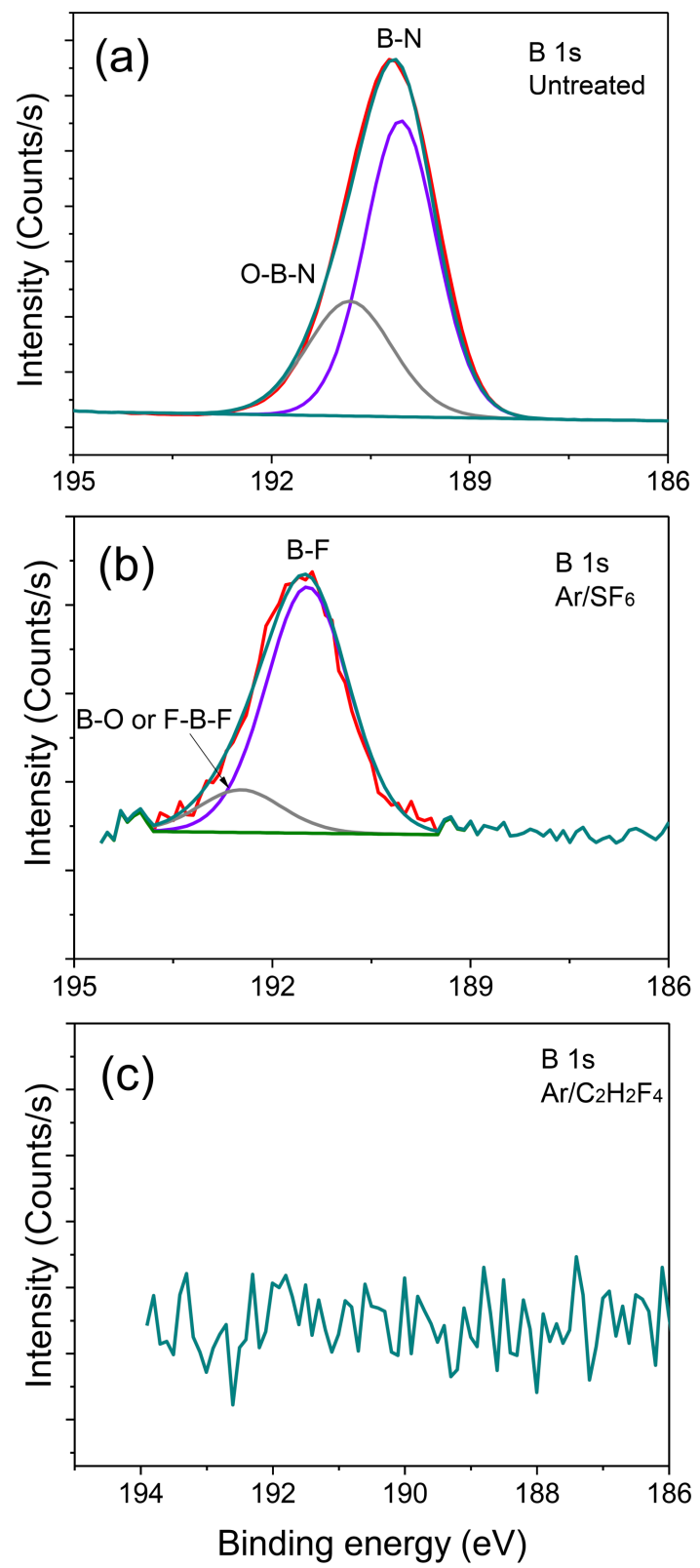

Fig. 4. High-resolution XPS spectra of the B $1 s$ core level for BNNS samples (a) before, and after plasma treatment in (b) $\mathrm{Ar} / \mathrm{SF}_{6}$ and (c) $\mathrm{Ar} / \mathrm{C}_{2} \mathrm{H}_{2} \mathrm{~F}_{4}$ plasmas.

B-O bond or F-B-F bond [28, 29]. This indicates that the surface of BNNS is completely oxidized/ fluorized after $\mathrm{Ar} / \mathrm{SF}_{6}$ plasma. In the case of $\mathrm{Ar} / \mathrm{C}_{2} \mathrm{H}_{2} \mathrm{~F}_{4}$ plasma no trace for $\mathrm{B} 1 s$ peak (Fig. 4c) was detected due to surface coverage with the fluorocarbon layer.

The N $1 s$ spectrum of the as-prepared BNNS sample (Fig. 5a) can be fitted by two curves. The intense one at $\sim 397.7 \mathrm{eV}$ can be assigned to $\mathrm{N}-\mathrm{B}$ bonds in h-BN [29, 33], whereas the other one centered at $\sim 398.7 \mathrm{eV}$ has been identified as a turbostratic structure (t-BN) attributed to the presence of $\mathrm{N}-\mathrm{O}$ and/or $\mathrm{N}-\mathrm{OH}$ bonds [29]. After treatment with $\mathrm{Ar} / \mathrm{SF}_{6}$ plasma, the BNNS sample showed a new peak positioned 

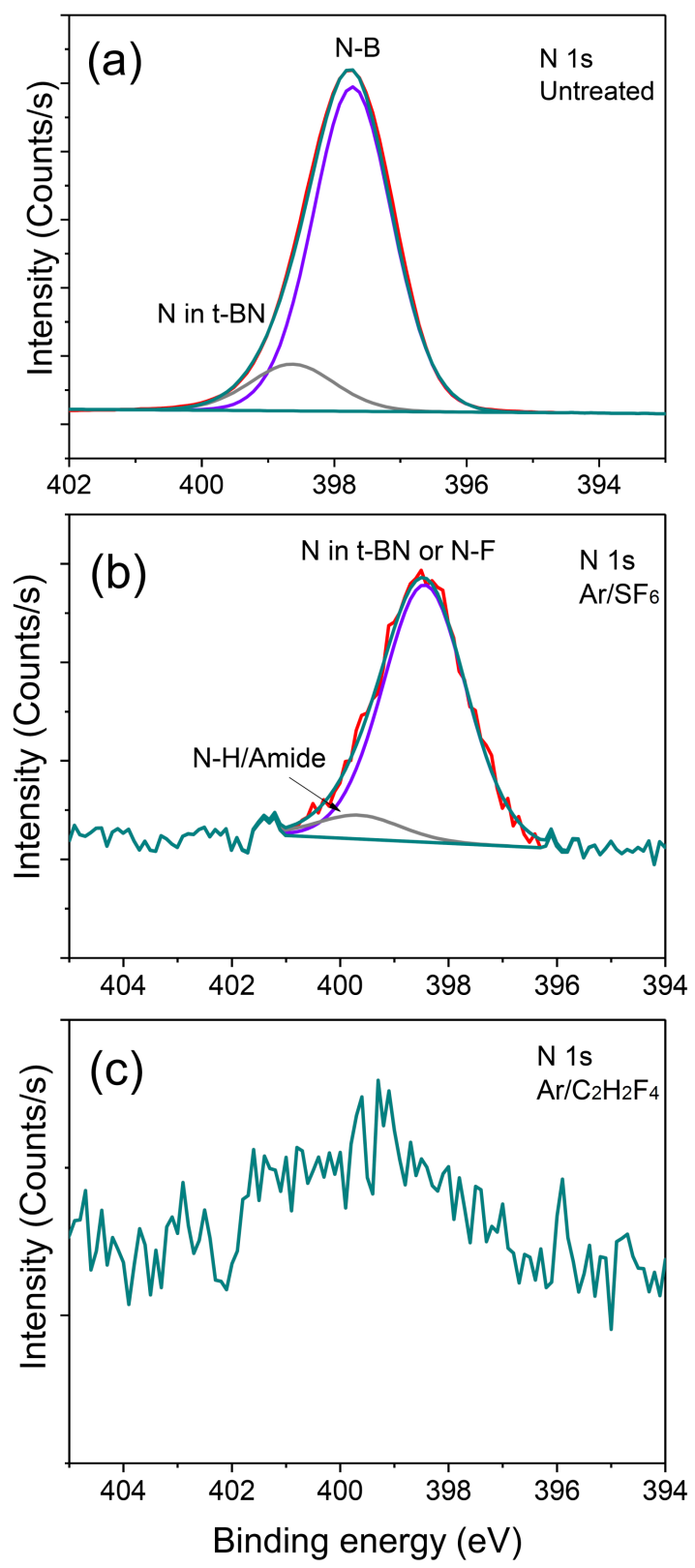

Fig. 5. High-resolution XPS spectra of the N $1 s$ core level for BNNS samples (a) before, and after plasma treatment in (b) $\mathrm{Ar} / \mathrm{SF}_{6}$ and (c) $\mathrm{Ar} / \mathrm{C}_{2} \mathrm{H}_{2} \mathrm{~F}_{4}$ plasmas.

at around $400.0 \mathrm{eV}$ (Fig. 5b) formed due to presence of $\mathrm{N}-\mathrm{H}$ bond [33] or amide group [29]. In addition, the peak related to $\mathrm{B}-\mathrm{N}$ bond completely disappears while a peak that can be attributed to t-BN or $\mathrm{N}-\mathrm{F}[31,32]$ becomes the most intense. This t-BN is already observed in HRTEM of BNNS after Ar/SF6 plasma covering the entire surface of BNNS walls. Again, the HRTEM are in accordance with the XPS analyses. In the case of $\mathrm{Ar} / \mathrm{C}_{2} \mathrm{H}_{2} \mathrm{~F}_{4}$ plasma, the $\mathrm{N} 1 s$ peak was not detected, because XPS is a surface characterization technique and fluorocarbon layer formed on the surface is thicker than the penetration depth of XPS analyses.
The F $1 s$ core peak (Fig. 6a) obtained for BNNS treated with $\mathrm{Ar} / \mathrm{SF} 6$ plasma is characterized by a main component at $685.6 \mathrm{eV}$. This value is very close to F linked to metals like lithium [34]. Since we did not find any XPS report in literature for boron-fluorine bonds in the case of $\mathrm{F} 1 s$ core level spectra, the main peak here could be assigned to $\mathrm{F}-\mathrm{B}$ bond. The energy position of the $\mathrm{F} 1 s$ in the BNNS treated with $\mathrm{Ar} / \mathrm{C}_{2} \mathrm{H}_{2} \mathrm{~F}_{4}$ plasma, shown in Fig. 6b, is about $686.6 \mathrm{eV}$, which can be compared to $686.9 \mathrm{eV}$ in poly(vinyl fluoride). Note, that F $1 s$ signal in Viton and poly(tetrafluoroethylene) is at 688.8 and $689.67 \mathrm{eV}$, respectively. This comparison suggests that in our case a $\mathrm{H}-\mathrm{C}-\mathrm{F}$ species are likely to be present on the surface [35]. This supports our suggestion of fluorocarbon layer formation on the surface of BNNS treated with $\mathrm{Ar} / \mathrm{C}_{2} \mathrm{H}_{2} \mathrm{~F}_{4}$ plasma.

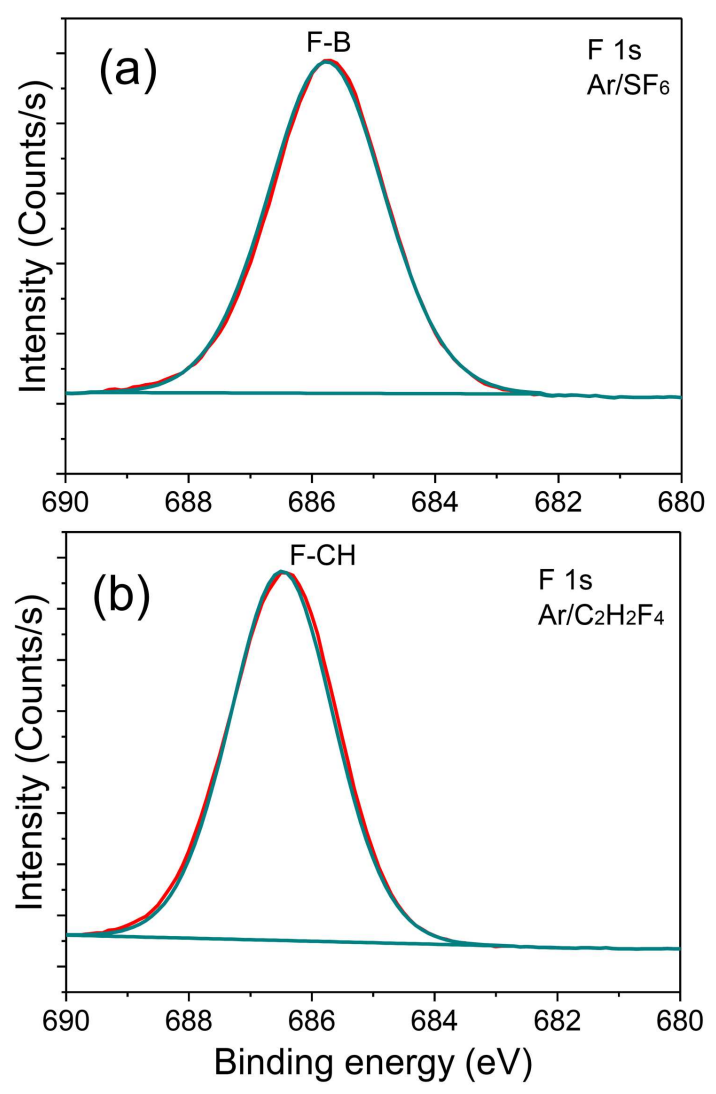

Fig. 6. High-resolution XPS spectra of the F $1 s$ core level for BNNS samples after plasma treatment in (a) $\mathrm{Ar} / \mathrm{SF}_{6}$ and (b) $\mathrm{Ar} / \mathrm{C}_{2} \mathrm{H}_{2} \mathrm{~F}_{4}$ plasmas.

Water contact angle (WCA) measurements were performed on all the samples, with the aim at assessing the effect of plasma treatment with $\mathrm{Ar} / \mathrm{SF}_{6}$ and $\mathrm{Ar} / \mathrm{C}_{2} \mathrm{H}_{2} \mathrm{~F}_{4}$ plasms on wetting characteristics of BNNS. The water contact angle (WCA) values of the as-prepared and plasma treated BNNS are shown in Fig. 7. The WCA values were noticed to increase from $\left(118.2^{\circ} \pm 2.3^{\circ}\right)$ for the as-deposited BNNS to $\left(137^{\circ} \pm 1.4^{\circ}\right)$ and $\left(167.9^{\circ} \pm 1.8^{\circ}\right)$ for the $\mathrm{Ar} / \mathrm{C}_{2} \mathrm{H}_{2} \mathrm{~F}_{4}$ and $\mathrm{Ar} / \mathrm{SF}_{6}$ plasma 
modified BNNS sample, respectively. This increase in the contact angle value reveals a relative change in the BNNS surface wettability from hydrophobic to highly hydrophobic and to super-hydrophobic in the case of plasma treatment in $\mathrm{Ar} / \mathrm{C}_{2} \mathrm{H}_{2} \mathrm{~F}_{4}$ and $\mathrm{Ar} / \mathrm{SF}_{6}$, respectively. It is a well-known fact that water repellent tendency of a solid surface depends on two factors: (i) the surface chemistry and functionality, and (ii) the surface micro/nano morphological features (i.e., surface roughness) [14].

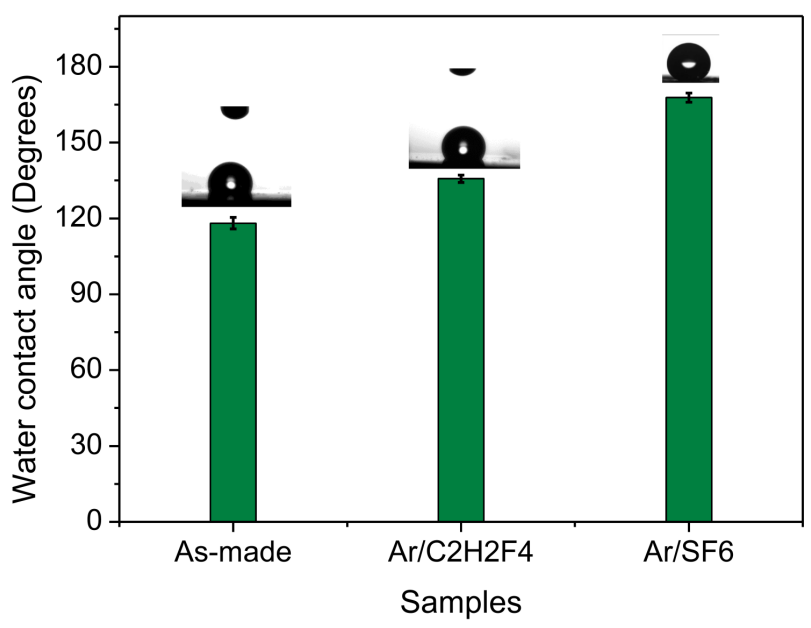

Fig. 7. Water contact angle measurements of the asproduced and plasma treated BNNS in $\mathrm{C}_{2} \mathrm{H}_{2} \mathrm{~F}_{4}$ and $\mathrm{SF}_{6}$ plasmas. The insets are typical photographs showing water droplets on the BNNS surface.

In the present case, we can have the contribution of both effects. Indeed, the surface mico-roughness seems to increase in the case of $\mathrm{Ar} / \mathrm{C}_{2} \mathrm{H}_{2} \mathrm{~F}_{4}$ plasma while it seems to be almost the same in the case of $\mathrm{Ar} / \mathrm{SF}_{6}$ plasma. Concerning the effect of surface chemistry (confirmed from XPS analysis), the presence of fluorocarbon layer on the surface of BNNS treated with $\mathrm{Ar} / \mathrm{C}_{2} \mathrm{H}_{2} \mathrm{~F}_{4}$ plays a key role on the improvement of hydrophobicity. Indeed, the presence of such a layer and its effect on the increase of water repellency has already been reported in the case of carbon nanowalls [36] and carbon nanotubes [19]. In the case of treatment by Ar/SF6 plasmas, there is a creation of new boron-fluorian bonds and radicals that could be the main agents for hydrophobicity enhancement and which may be even more hydrophobic than $\mathrm{C}-\mathrm{F}$ bonds.

The cold plasma surface treatment is usually employed to rend the BN based nanostructures hydrophilic [10, 12]. Indeed, to the best of the authors' knowledge, this is the first time the cold plasma treatment is used to increase the hydrophobicity of BN based nanostructures. In addition, the cold plasma process is cheap, controllable, and scalable, which makes it promising tool at the industrial level. In addition, although, $\mathrm{Ar} / \mathrm{C}_{2} \mathrm{H}_{2} \mathrm{~F}_{4}$ plasma treatment did not induce a considerable increase of hydrophobicity, but fluorinated coatings are well known to create low energy [37], biocompatible [38], or relatively inert surfaces with ambient air [39]. Therefore, coating BNNS with fluorinated coatings can find applications in biomedical cases, while super-hydrophobic BNNS that were treated in $\mathrm{Ar} / \mathrm{SF}_{6}$ plasma can find applications in self-cleaning coating for harsh environment or oil-water separation equipment.

\section{Conclusions}

We have shown that the post-synthesis plasma treatments can change the BNNS morphology and surface chemistry upon plasma treatment with a gas mixture of $\mathrm{Ar} / \mathrm{SF}_{6}$ or $\mathrm{Ar} / \mathrm{C}_{2} \mathrm{H}_{2} \mathrm{~F}_{4}$. The initial and treated states of BNNS were characterized by SEM, TEM, and XPS spectroscopy. The morphological modifications are caused by plasma erosion of the edges in the case of $\mathrm{Ar} / \mathrm{SF}_{6}$ plasma or by deposition of thin conformal films in the case of $\mathrm{Ar} / \mathrm{C}_{2} \mathrm{H}_{2} \mathrm{~F}_{4}$ plasma. In addition, depending on the gas mixture used, the plasma treatment of BNNS leads to the formation of different functional groups such as fluoro-boron and fluorocarbon on the surface. Regarding the effect of such treatments on wettability: $\mathrm{Ar} / \mathrm{C}_{2} \mathrm{H}_{2} \mathrm{~F}_{4}$ treatment made BNNS more hydrophobic with an increase of water contact angle (WCA) from $118.2^{\circ}$ to $137.0^{\circ}$, while $\mathrm{Ar} / \mathrm{SF}_{6}$ made BNNS super-hydrophilic with a WCA as high as $167.9^{\circ}$. The increase of WCA is mainly attributed to surface roughness increase in the case of $\mathrm{Ar} / \mathrm{C}_{2} \mathrm{H}_{2} \mathrm{~F}_{4}$ plasma, while in the case of $\mathrm{Ar} / \mathrm{SF}_{6}$ it is believed that the surface chemistry modification is the main responsible factor for converting BNNS from hydrophobic to superhydrophobic. The presented results are important for targeted utilization of BNNS as super-hydrophobic smart coating that can operate at high temperatures and harsh environment.

\section{Acknowledgments}

The research was financially supported by the Research Project of Educational Commission of Hubei Province, China (Project No. B2017296) and Hubei Natural Science Foundation, China (Project No. 2018CFC876).

\section{References}

[1] X. Wanga, Y. Yang, G. Jiang, Z. Yuan and S. Yuan, Diam. Relat. Mater. 81, 89 (2018).

[2] D.H. Cho, J.S. Kim, S.H. Kwon, C. Lee and Y.Z. Lee, Wear302, 981 (2013).

[3] Y. Zhan, J. Yan, M. Wu, L. Guo, Z. Lin, B. Qiu, G. Chen, K.Y. Wong, Talanta 174, 365 (2017).

[4] W. Lei, D. Portehault, D. Liu, S. Qin, Y. Chen, Nat. Commun. 4, 1 (2013).

[5] J. Talat, M. Sabzi, B. Safibonab, I. Hasanzadeh, A. Arman, I. Karimzadeh, J. Nanosci. Nanotechnol. 18, 1110 (2018). 
[6] A. Achour, B.E. Belkerk, K.A. Aissa, S. Vizireanu, E. Gautron, M. Carette, P.Y. Jouan, G. Dinescu, L.L. Brizoual, Y. Scudeller, M.A. Djouadi, Appl. Phys. Lett. 102, 061903 (2013).

[7] B.E. Belkerk, A. Achour, D. Zhang, S. Sahli, M.A. Djouadi, Y.K. Yap, Appl. Phys. Express 9, 075002 (2016).

[8] L.H. Li and Y. Chen, Adv. Funct. Mater. 26, 2594 (2016).

[9] Q. Weng, X. Wang, X. Wang, Y. Bando, D. Golberg, Chem. Soc. Rev. 45, 3989 (2016).

[10] L. Li, L.H. Li, S. Ramakrishnan, X.J. Dai, K. Nicholas, Y. Chen, Z. Chen, X. Liu, J. Phys. Chem. C 116, 18334 (2012).

[11] C.H. Lee, J. Drelich, Y.K. Yap, Langmuir 25, 4853 (2009).

[12] H. Achour, A. Achour, S. Solaymani, M. Islam, S. Vizireanu, A. Arman, A. Ahmadpourian, G. Dinescu, Diam. Relat. Mater. 77, 110 (2017).

[13] A. Pakdel, Y. Bando, D. Golberg, ACS Nano 8, 10631 (2014).

[14] A. Pakdel, C. Zhi, Y. Bando, T. Nakayama, D. Golberg, ACS Nano 5, 6507 (2011).

[15] X. Li, H. Qiu, X. Liu, J. Yin, W. Guo, Adv. Funct. Mater. 27, 1603181 (2017).

[16] S. Das, S. Kumar, S.K. Samal, S. Mohanty, S.K. Nayak, Ind. Eng. Chem. Res. 57, 2727 (2018).

[17] S. Lee, W. Kim, C. Yim, K. Yong, S. Jeon, RSC Adv. 9, 761 (2019).

[18] J. Li, F. Du, X. Liu, Z. Jiang, L. Ren, J. Bionic Eng. 8, 369 (2011).

[19] L.B. Zhu, Y.H. Xiu, J.W. Xu, P.A. Tamirisa, D.W. Hess, C.P. Wong, Langmuir 21, 11208 (2005).

[20] A.B. Gurav, S.S. Latthe, R.S. Vhatkar, J.G. Lee, D.Y. Kim, J.J. Park, S.S.Yoon, Ceram. Int. 40, 7151 (2014).

[21] J. Zhou, M.A. Frank, Y. Yang, A.R. Boccaccini, S. Virtanen, Mater. Sci. Eng. C 82, 277 (2018).

[22] L.H. Li, J. Cervenka, K. Watanabe, T. Taniguchi, Y. Chen, ACS Nano 8, 1457 (2014).

[23] A. Pakdel, X. Wang, C. Zhi, Y. Bando, K. Watanabe, T. Sekiguchi, T. Nakayama, D. Golberg, J. Mater. Chem. 22, 4818 (2012).

[24] A. Zobelli, A. Gloter, C.P. Ewels, G. Seifert, C. Colliex, Phys. Rev. B 75, 245402 (2007).
[25] M. Sajjad, G. Morell, P. Feng, Adv. Mater. Interfaces 5, 5051 (2013).

[26] P. Feng, M. Sajjad, E.Y. Li, H. Zhang, J. Chu, A. Aldalbahi, G. Morell, Beilstein J. Nanotechnol. 5, 1186 (2014).

[27] D. Golberg, M. Mitome, Y. Bando, C.C. Tang, C.Y. Zhi, Appl. Phys. A 88, 347 (2007).

[28] X.J. Dai, Y. Chen, Z. Chen, P.R. Lamb, L.H. Li, J.D. Plessis, D.G. McCulloch, X. Wang, Nanotechnol. 22, 245301 (2011).

[29] B.B. Wang, M.K. Zhu, K. Ostrikov, I. Levchenko, M. Keidar, R.W. Shao, K. Zheng, D. Gao, Carbon 109, 352 (2016).

[30] C. Guimon, D. Gonbeau, G. Pfister-Guillouzo, O. Dugne, A. Guette, R. Naslain, M. Lahaye, Surf. Interface Anal.16, 440 (1990).

[31] S. Radhakrishnan, J.H. Park, R. Neupane, C.A. de los Reyes, P.M. Sudeep, M. Paulose, A.A. Martí, C.S. Tiwary, V.N. Khabashesku, O.K. Varghese, B.A. Kaipparettu, P.M. Ajayan, Part. Part. Syst. Charact. 36, 1800346 (2019).

[32] S. Radhakrishnan, D. Das, A. Samanta, C.A. de los Reyes, L. Deng, L.B. Alemany, T.K. Weldeghiorghis, V.N. Khabashesku, V. Kochat, Z. Jin, P. M. Sudeep, A.A. Martí, C.W. Chu, A. Roy, C.S. Tiwary, A.K. Singh, P.M. Ajayan, Sci. Adv. 3, 1700842 (2017).

[33] S.B. Ponraj, Z. Chen, L.H. Li, J.S. Shankaranarayanan, G.D. Rajmohan, J. du Plessis, A.J. Sinclair, Y. Chen, X. Wang, J.R. Kanwar, X.J. Dai, Langmuir 30, 10712 (2014).

[34] L. Martin, H. Martinez, D. Poinot, B. Pecquenard, F.L. Cras, J. Power Sources 248, 861 (2014).

[35] R.Y. Korotkov, T. Goff, P. Ricou, Surf. Coat. Technol. 201, 7207 (2007).

[36] S. Vizireanu, M.D. Ionita, G. Dinescu, I. Enculescu, M. Baibarac, I. Baltog, Plasma Process. Polym. 9, 363 (2012).

[37] T. Nishino, M. Meguro, K. Nakamae, M. Matsushitaand, Y. Ueda, Langmuir 15, 4321 (1999).

[38] D. Kiaei, A.S. Hoffman, T.A. Horbett, K.R. Lew, J. Biomed. Mat.Res. 29, 729 (1995).

[39] M. Sarmadi, Y. Kwon, Textile Chem. Color. 25, 33 (1993). 